\title{
Tourist navigation through historical sites: the spatial analysis approach
}

\author{
N. I. Mohareb ${ }^{1}$, A. G. ElAdawi ${ }^{2}$ \& H. M. Ayad ${ }^{2}$ \\ ${ }^{I}$ Department of Architectural Engineering, UAE University, UAE \\ ${ }^{2}$ Department of Architectural Engineering, Alexandria University, Egypt
}

\begin{abstract}
Historical sites represent a valuable cultural memory and a testimony of passage of time in Arab-Islamic cities. They represent one of the tourist attraction points to navigate through time and culture within a number of significant morphological sites. Consequently, most governmental agencies carry out plans for upgrading and conservation of those sites, in order to maximize the economic and cultural benefits from the tourist interests as well as to maintain and improve the local morphological characters and the traditional user's activities.

This research highlights a major problem that has to be taken into account when setting those plans, which is the location of the start/end dropping point for tourist tours. These points usually affect the tourist's ability to grasp most of the historical site in an adequate time and with less effort. In addition, they will affect the economic and socio-cultural activities which the government seeks to upgrade and benefit from, through deciding what, where, and how the tourist will grasp the historical site.

The research will explore a number of methods on how to locate and arrange the dropping points for tourists from the spatial configuration point of view, taking into account the other users activities and interests. The research will depend on 'space syntax' as a base investigation quantitative method, in addition to other qualitative methods to verify the outcomes. Historical Cairo is selected to be the case study to analyze and test these methods.
\end{abstract}

Keywords: tourist navigation system, space syntax, tourist's dropping points.

\section{Tourist navigation system}

This research's main concern is how to manage and design a tourist tour in a historical site, with a special emphasis on identifying the main start/end points of 
navigation toward and through the site. A review of a number of researches and projects concerning upgrading different locations in Cairo and Alexandria has revealed that the issue of defining start/end points of tourist's navigation was usually neglected to a great extent.

This research is an intermediate part of a larger project. It will highlight the importance of identifying the potential start/end points for navigation in historical sites from the spatial configuration point of view, defining a number of techniques and methods that could be applicable in selecting the correct point's location.

\section{Planning for navigation}

Before setting any possible tourist path, two main questions need to be addressed. Firstly, why it is important to define start/end points, and secondly, how to define them an appropriate way.

To answer the first question, from a previous part of the project, a number of interviews were held by the researchers using the one-to-one interview method with tourists and professionals from governmental agencies and NGOs. In summary, the tourist's opinion is that the start/end points represent a first impression and an image as to what is going to be seen next, and as a result, a clue for how much time it is desirable to spend at that place. Moreover, it was noticed that their main concern for the individual tourist - without guidance was the degree of accessibility of those points and whether they lead in a legible way toward the historical sites. Finally, the type and quality of transportation to start/end points is of great impact on the tourist's experience and ease of accessibility.

From the interviews, having a designed start/end dropping point is an important issue, and defining a location for it is the most problematic one. The inappropriate location will lead to chaos in the type of activities, and the pattern of movement for any new intervention to upgrade. In addition, the local users will not benefit (participate) economically, in addition to the segregation of socio-cultural activities, thus leading to deterioration for the historic sites over long periods. A dropping point located too close to the historical site will not have the benefit of introducing new activities in relation to the historical site, moreover a location too far away will cause the tourist trip to be time consuming, which may lead to exhausting and uncompleted tours inside the historical site (time/lose interest, etc.).

Regarding the second question, on how to define the start/end points, this shall be discussed in the following research methodology.

\section{Research methodology}

The selected methodology is based on identifying the different types of tourist movement patterns, exploring their different routes of navigation inside historical sites, analyzing the morphology of urban historical spaces, particularly the spatial morphology of the urban fabric, and finally, identifying a criterion for selecting start/end point locations. There are a number of tools and techniques 


\begin{tabular}{|c|c|c|}
\hline What to study? & Outcome & How to study? \\
\hline $\begin{array}{l}\text { Tourist's pattern } \\
\text { of movement }\end{array}$ & $\begin{array}{l}\text { Tourist's pattern of movement } \\
\text { Time Span / Distance convered }\end{array}$ & $\begin{array}{l}\text { Tracing people } \\
\text { Field Survey }\end{array}$ \\
\hline $\begin{array}{l}\text { Spatial Morphology } \\
\text { Grid pattern } \\
\text { Physical pattern }\end{array}$ & $\begin{array}{l}\text { Potential pedestrian movement } \\
\text { Potential successful activities location } \\
\text { Tourist potential interest affecting: } \\
\text { Visual/ Speed/ Densities/ Safety } \\
\text { Landmarks } \\
\text { Interested Places } \\
\text { Historical Buildings Location } \\
\text { Starting/ Ending } \\
\text { Navigation Points }\end{array}$ & $\begin{array}{l}\text { Space Syntax } \\
\text { Integration / Choice } \\
\text { Directional pattern } \\
\text { Space Syntax } \\
\text { Point/ Step Depth } \\
\text { Urban Block Size } \\
\text { VGA analysis } \\
\text { Field survey } \\
\text { Land use } \\
\text { Entrances } \\
\text { Building Frontage }\end{array}$ \\
\hline
\end{tabular}

Figure 1: The framework of the research.

used, namely space syntax as an analytic quantitative method and field surveillance for the tourist pattern of movement, in addition to the visual survey to capture the main visual interests (fig. 1).

\section{Exploring the potential pattern of movements in historical sites}

In order to explore the possible movement patterns, two main types of tourists were selected: group tourists (with/without a guide), and individual ones. According to a tourist agency interview the group tourists usually have less time available for exploration, due to the limitation of time in schedules. Normally, the individual tourist has the ability to manage his own visit schedule with relatively more flexible time for navigation.

Hillier and Iida [1] argued that movement is essentially a linear activity; interaction requires a space, that can be named as "convex space", in which people could be aware of anything located inside it. That explains how people could move in space. Regarding the tourist, they need to identify two things: the location of their required destination (Magnet), in addition to the selection of routes leading to their destination. These two points have an affect on selecting the start/end location. Furthermore, a number of other factors, such as the topographic location of the site, weather conditions, economic conditions, etc. could affect the way they explore historical sites.

\section{Analyzing the current situation}

As previously explained, time and distance are main factors affecting the ability of the tourist to navigate through historical sites. Consequently, the location of start/end points will have a direct influence on those two points. In this part, using the field survey method and space syntax techniques, the research will attempt to establish an understanding of the pattern of movement of tourists within historical Fatimid Cairo, as a case study for the research. 


\subsection{Visual and field survey}

A field survey was held by the researcher to understand the main visual location for the tourists' key magnets (historical buildings/activities). In addition, the tourist interactivity and pattern of movement was studied in order to analyze the relationship between the building frontages and to identify the current dropping points (start/end) for the tourists' trip.

\subsubsection{Field survey; building frontage, entrances, pedestrian densities}

From the field survey and pedestrian surveillance, it was found that there is a strong relation between pedestrian movement and the type of building frontage (ground floor). This technique was used by space syntax and through William Weight's research to understand the pattern of movement. The more transparent façade in addition to the number of entrances found in the historical sites (related to commercial activities rather than residential ones) the more interactive the pedestrian with the activities. As a result, it slows down their speed of movement (fig. 2). This was obvious in Khan El_Khalili comparing to Wekala QuidBay (fig. 3). As part D, E, F in fig. 2 (left) is more interactive for the tourist users, while $\mathbf{A}, \mathbf{B}, \mathbf{C}$ are interactive for the local users. In another survey regarding the speed of movement (timing) relating to walking distance, it was found that different users have different speeds in relation to time and type of activities found in the context, and this is an important issue when trying to figure out (time/distance) in any navigation path for the tourist (fig. 4).
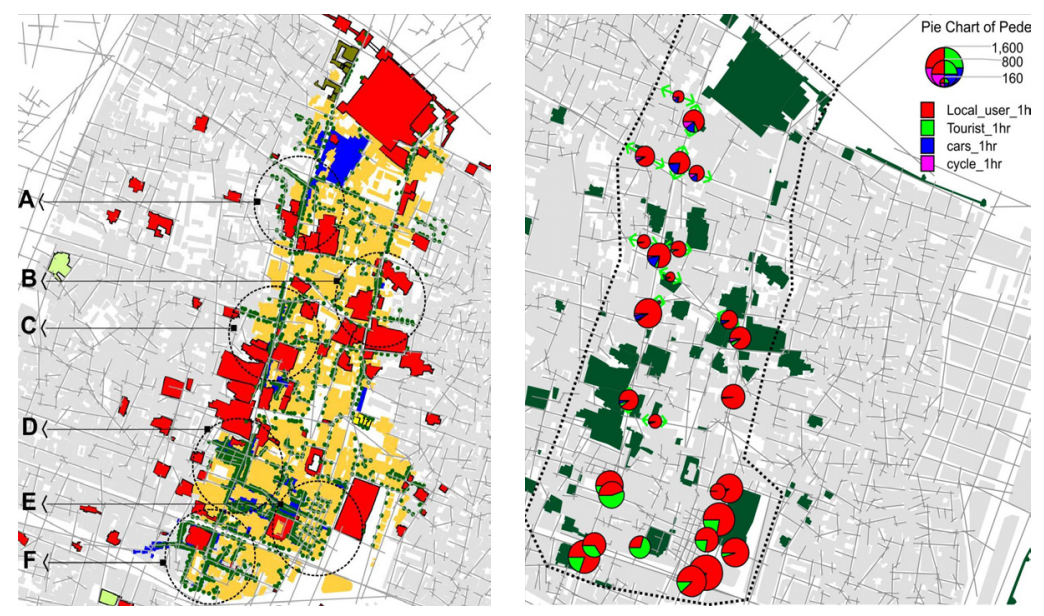

Figure 2: (Left) Entrance map analysis for the central part of Fatimid Cairo. (Right) Pedestrian movement observation (local users/tourists).

\subsection{Quantitative analytic method: space syntax}

Space syntax has been selected as a theory and a tool in this research for a number of reasons. Firstly, it works across scales [2]: it is initially based on 
street-scale data, and this is important as it is at the level of which people experience the city, where they meet, intersect and carry out economic and social transactions. Secondly, space syntax is equally able to aggregate from microscale up to the most macro, without either losing sight of the other. Thirdly, it describes the non-discursive relationships of spaces within the same site or as a comparison between different sites (different scale). Finally it could measure different types of correlations [3] between space-people, space-space and peoplepeople.

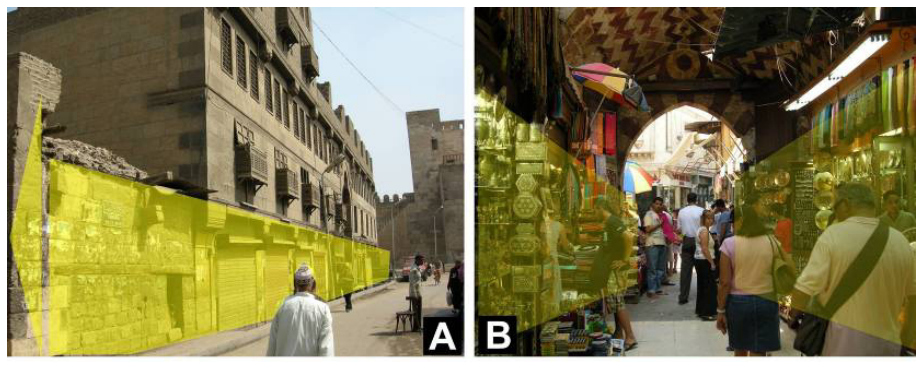

Figure 3: A visual surveys for the buildings frontage. In example $\underline{A}$ the ground floor is not transparent, and does not encourage interactivity, in contrast to example $\underline{B}$ (Khan El Kalili).

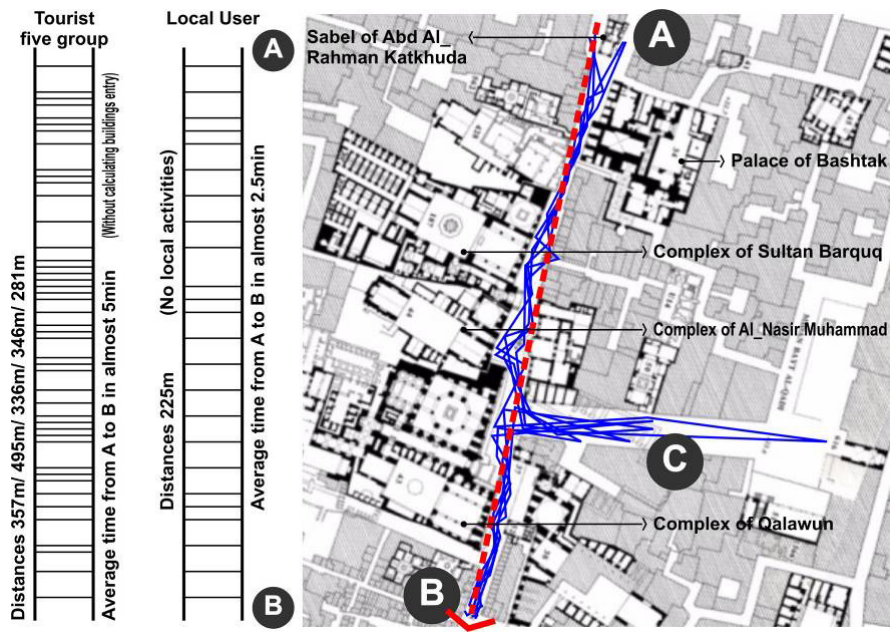

Figure 4: $\quad$ Field observation of two different types of users (local users and groups of tourist) has been observed. The graphic on the left represents the speed of movement (time) with relation to the interval of time taken for both users. The total distance was $225 \mathrm{~m}$, the average time for local users were $2.5 \mathrm{~min}$ (no interesting activities to them), while the average for the tourist groups were 5 min (almost double the time). 


\subsubsection{Understanding the location of historical (buildings/activities) in relation to the pattern of movement}

Using the space syntax approach in understanding the configuration of the deformed grid in historical Cairo, Choice Analysis has been used to understand the 'through movement' of historical Cairo. By definition, it is the degree to which each element lies on a path between elements, and that is its potential for 'through-movement' [4]. It was found that almost $83 \%$ of the historical (buildings/activities) (the total buildings studied were 188, and 155 buildings were correlated with choice R $800 \mathrm{~m}$ ) lay on the highest $10 \%$ of selected routes on Choice R800m analysis. It shows how those building are located in precisely selected points in relation to the urban pattern configuration (fig. 5 (right)). Most of the important historical buildings and activities form a heritage corridor as in fig. 5 (left), and that gives a clear image on their distribution. Consequently and from the previous parts of the research, a number of start/end point locations of potential navigation paths are hypothesized, as they could cover most of the navigation scenarios (fig. 5 (left)). Gates $\mathbf{C}$ and $\mathbf{B}$ are the current start/end points frequently used by most of tourist agents.
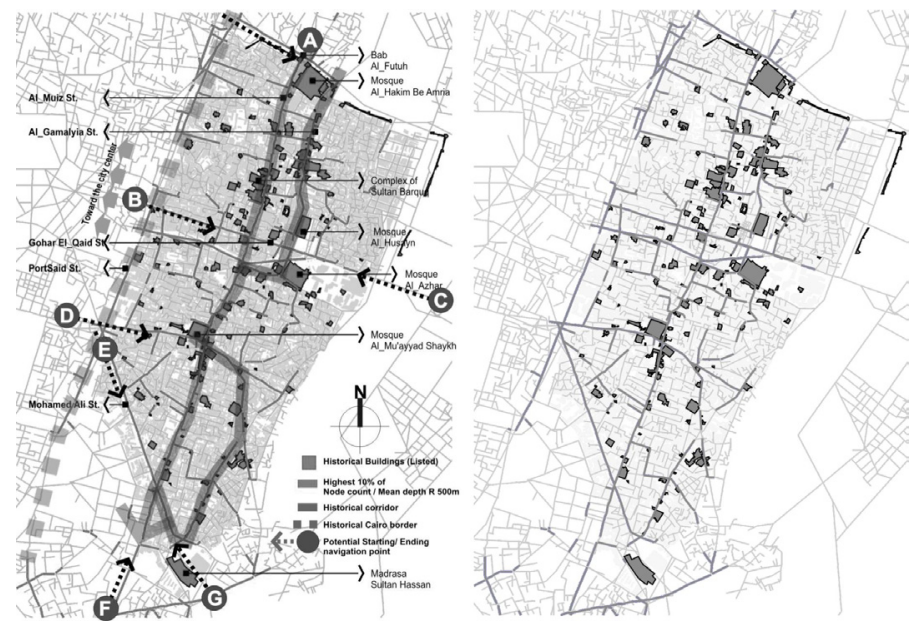

Figure 5: (Left) map represents the main heritage corridor and the potential entrances (start/end) points for the historical Cairo. (Right) location of the historical building in relation with the highest $10 \%$ of selected routes in the Choice segment map R $800 \mathrm{~m}$ (local choice).

\subsubsection{Nodes and paths}

Hypothesized start/end point locations will be examined on the level of the points and paths connected to them, to have a total perception considering not just the point's location, but also how it is connected to its path.

Spaces syntax's point depth technique is used to examine the actual distance coverage between these points and the historical Cairo buildings and activities. 
Walking ranges are based on actual distance for the routes available for pedestrians, counting their different changes in direction to the final destination, rather than using a circular boundaries measurement (which gives an untrue distance), especially in the deformed grid patterns of historical Cairo. Isochrones show as concentric circles. Fig. 6 gives a clear image regarding walking distance equal to $\mathbf{1 ~} \mathbf{~ k m}$ coverage for each of the hypothesis points, it is equivalent to 10 min walking [5], taking into consideration that $10 \mathrm{~min}$ is not the tourist walking speed as discussed previously in part 5.1.1.
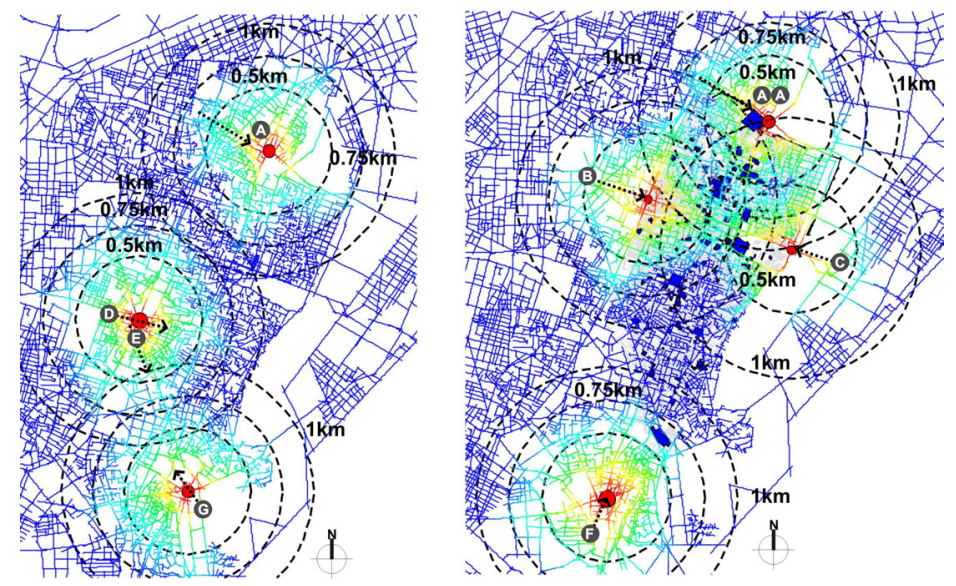

Figure 6: Both figures represent the point depth analysis for the different alternative potential start/end points of navigation within $1 \mathrm{~km}$.

Step depth is used to understand the local grids crossing along specific routes [3], and that is practical to understand the tourists path's connection with the surrounding 2 and 3 step routes connected to them. Fig. 7 illustrates the major almost vertical routes in historical Cairo: inner routes (El_Gamalyia St., El_Muiz St. and El_Guriya_El_Kyamia St.) and the border routes (PortSaid St.). In addition to the major almost horizontal routes in historical Cairo are Gohar El_Qaid St., El_Azhar St. and Mohammed Ali St., and they are well connected with the outer boundaries (fig. 8).

From figs. 7 and 8 we can exclude a number of streets to be the starting points, as they are not well connected with historical Cairo, although they could be excellent ending points, due to their connection with Cairo city centre. As an example: Mohammed Ali St., El-Azhar St. and Port Said St.

\subsubsection{Permeability analysis}

In this part of the research, the degree of permeability of each main route will be examined using block size ratio, and the main routes direction. Hillier argued that when block size is small, you are closer to all the buildings that make up the block than when they are large [4]. Fig. 9 illustrates the block size ratio weighted by the plot size. The old fabric composed of residential and historical religious 


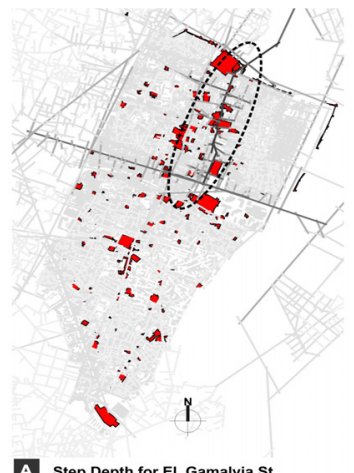

A Step Depth for El_Gamalyia St.

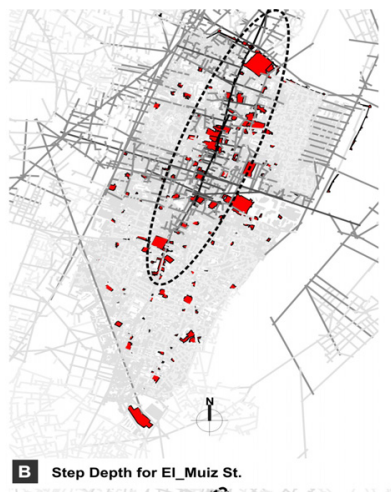

B Step Depth for El_Muiz St.

Figure 7: $\quad$ Step depth map analysis for the main vertical routes.
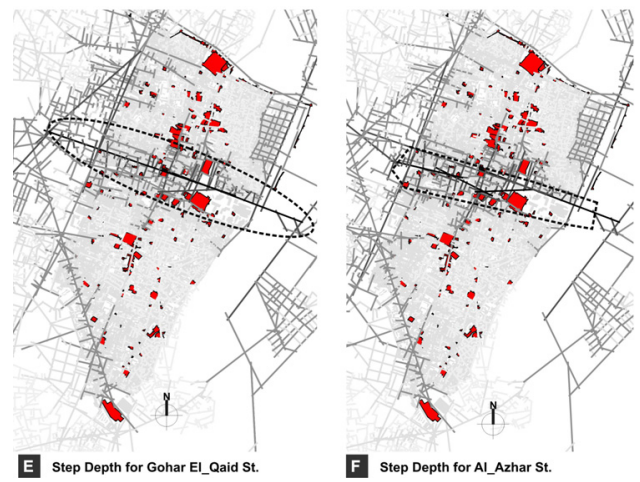

F Step Depth for Al_Azhar St.

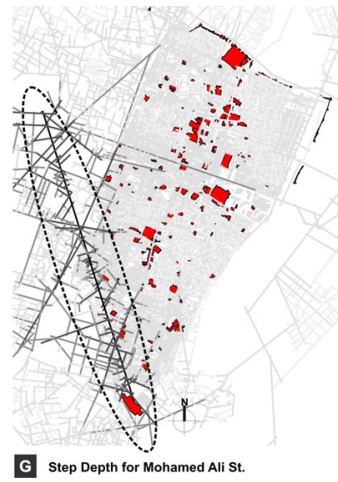

G Step Depth for Mohamed Ali St.

Figure 8: $\quad$ Step depth map analysis for the main horizontal routes.

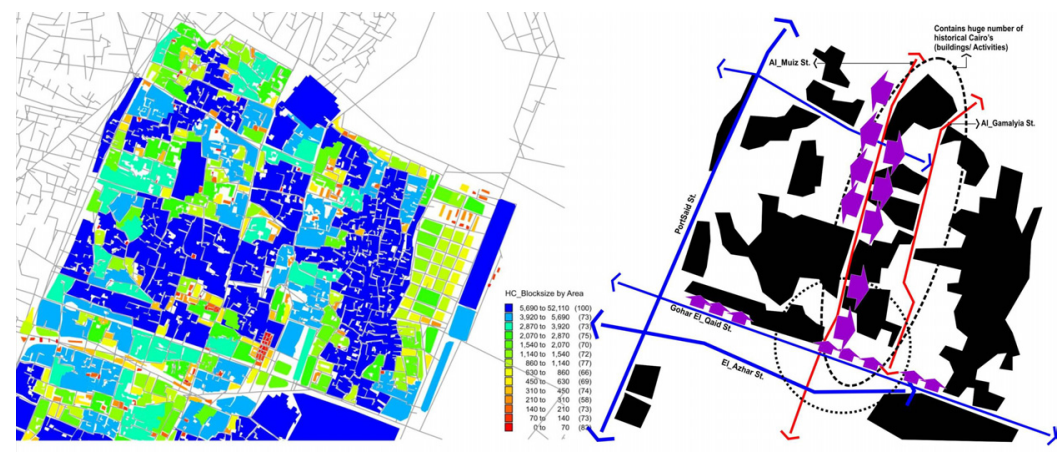

Figure 9: (Left) Block size analysis, gradient from dark gray color, indicates the huge blocks, to mid-gray, indicating the smaller blocks. (Right) Illustration of the major blocks and main route permeability in Fatimid Cairo. 

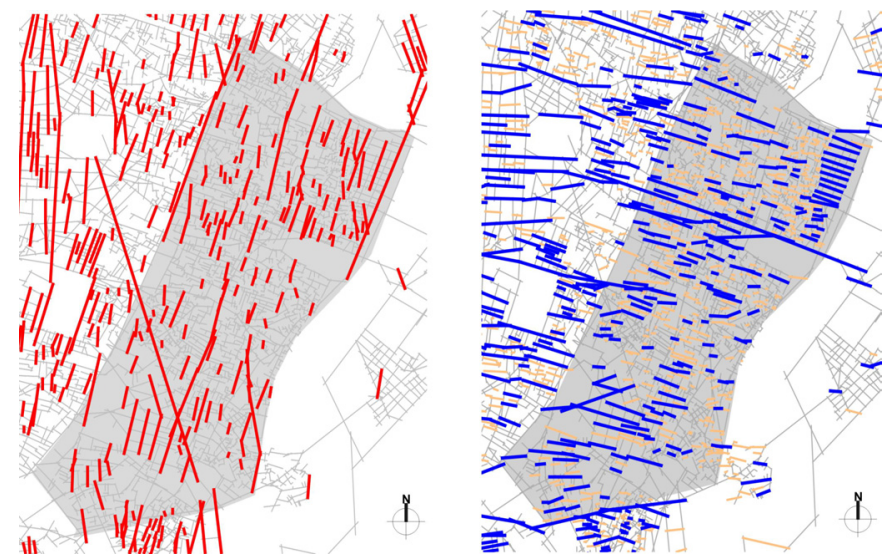

Figure 10: Main direction routes analysis in historical Cairo.

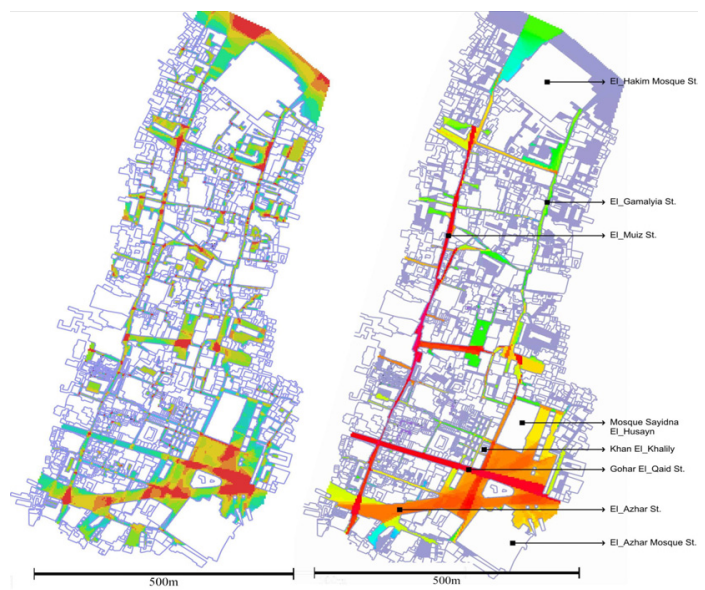

Figure 11: VGA analysis (left) controlling points, (right) map for integration for partial part of Fatimid Cairo (El-Muiz St. \& El-Gamalyia St.).

buildings forms the majority of the huge blocks. In addition, these blocks are penetrated by 'Hara' or 'Atfa' (the majority are dead end streets) forming less permeability for 'outsider users' pedestrian movement in their urban fabric. By examining the main routes in Fatimid Cairo there are three main routes that face fewer of these blocks namely: El-Muiz St., El-Gamalyia St. and Gohar El-Qauid. While Gohar El-Quid contains most of the historical commercial activities, namely a huge part from Khan El-Khalili, El-Muiz and El- Gamalyia St. contains most of the historical monuments with a more permeable access through them rather than Gohar El-Quid. Moreover, Gohar El-Qauid St. is not well connected to the other horizontal routes, although it contains almost all the livable activities which attract the tourists, it gives no chance for expansion of those activities. 
Fig. 10 represents that situation, the routes selection was filtered by selecting the ones with greater than or equal to the 3 -connectivity degree. That filter was used to exclude the 'dead end' routes and the poorly less important connected route to the total system. Fig. 10(left) illustrates the North-South main routes, while fig. 10 (right) represents the main dominant direction East-West direction routes (almost $60 \%$ more routes than the North-South).

\subsubsection{Visual Graph Analysis (VGA)}

The VGA map analysis measures a 2D inter-visibility of open space layout [3], it measures the relation between each node and another visible one. It draws the visual field from each point of a fine tessellation filling the layout, overlaps these so that an overlap counts as a connection, and calculates how many visual fields are needed to get to see the whole layout from any point within it. More red colors (lighter gray) indicate more visual integration through to blue (darker gray) color for the least [4] (fig. 11).

From fig. 11, it is obvious that El-Muiz St. and Gohar El-Quaid are the most visual integration routes. Furthermore, El- Muiz St. has more controllable points than Gohar El-Quaid.

\section{Aggregate the outputs}

The previous morphological and spatial analyses form a comprehensive understanding to the current situation and represent the base criteria to select the appropriate locations for start/end points of navigation for the tourists through historical Cairo. In fig. 5, seven possible gates could be used for both starting and ending points. Gates $\mathbf{D}, \mathbf{E}, \mathbf{G}$ and $\mathbf{F}$ could be excluded, as they are too far (distance and time) from the majority of the historical buildings/activities (fig. 6); in addition, they are located on Mohammed Ali St and Port Said St., which are connected with the city center more than the historical sites, although Gate $\mathbf{G}$ could be used as a starting point if the trip will start from the Cairo Citadel and continue to historical Cairo. Gates $\mathbf{A}, \mathbf{B}$ and $\mathbf{C}$ represent the nearest points to the majority of the historical buildings/activity. Gate $\mathbf{C}$ is the major currently selected starting point, although from fig. 9, it passes through huge blocks, with a solid frontage, which means a long distance with no appropriate activity. Furthermore, for Gates $\mathbf{B}$ and $\mathbf{C}$ the main heading is toward Khan El-Khalili, a famous historical commercial place in historical Cairo. As a result, two negative issues could be stated: firstly, due to the huge number of entrances and the transparent frontage for Khan El-Khalili, the tourist will be forced to spend most of his time in this area without being able to visit the rest of historical Cairo. Secondly, as depicted in fig. 10, Gohar El_Quid St. is not well connected with other horizontal routes and the surrounding environment and could better serve as an ending point. As a result, point $\mathbf{A}$ is the ideal appropriate starting point for the tourist through historical Cairo for the following reasons: from outside the fence, it gives a mystery image on what is located behind that fence, going through Bab El_Fetouh gate and through EL_Muiz St. it has the most visual integration and points of control (fig. 11). In addition, it has an appropriate number of entrances, meaning that more tourists will experience better 
interactivity with the surrounding context. Moreover, it contains a huge number of important historical monuments. According to fig. 7(b), it is well connected with El_Gamalyia St., KhanAl_Khalili area and the surrounding context.

\section{Conclusion}

Throughout the research, planning the location and activities accomplished with the start/end dropping points enhanced any upgrading process to the sustainable tourism plans for historical sites. In addition, they represent the first/last image and sense of space for the historical sites. Their location needed to be planned carefully using the following points: taking advantage of the current urban fabric morphology to locate the best location of the dropping points (integrated locations), inserting new appropriate activities or revive old ones, as those activities control the speed, time and movement orientation for the tourist pedestrian pattern of movement. In addition, linking those points with a suitable transportation system will enhance accessibility plans for the historical sites. The research suggested an aggregation set of tools based on the qualitative and quantitative method to be able to understand the current situation and plan for setting the start/end dropping points in their appropriate location, based mainly on a field survey, one-to-one interviews and space syntax to understand the spatial deformed grid of the historical site.

Regarding historical Cairo, the current start/end points are not the appropriate successful ones. The successful start/end point locations have to accommodate with the total overview perspective for the historical site as one entity and fit with the plans for upgrading. The research discovered that most of the historical buildings/activities, almost $83 \%$, lay on the highest $10 \%$ of local 'through movement' routes. Furthermore, the site locations have been carefully selected to be used in the daily life of pedestrian movement (fig. 5), and that gives a clue that they have a strong criterion for site selection to their important buildings/activities. This issue should be urgently taken into consideration in introducing new activities or start/end point locations.

\section{References}

[1] Hillier, B. and S. Iida. Network effects and psychological effects, In 5th International Space Syntax Symposium. 2005. University of Delft.

[2] Hillier, B. and L. Vaughan, The City as one Thing. 2007.

[3] Syntax, S., Fifth Framework Programme: AGORA cities for People. 2004, The London Institute: London.

[4] Hillier, B., The art of place and the science of space. World Architecture, 2005.

[5] Rapoport, A., History and Precedent in Environmental Design. 1990, New York and London: Plenum Press.

[6] Warner, N., The Monuments of Historic Cairo: A map and Descriptive Catalogue. Conservation Series. Vol. 1. 2005, Cairo: The American University in Cairo Press. 